\title{
Using Technology to Promote Active and Social Learning Experiences in Health Professions Education
}

\author{
Elizabeth Ruckert, Paige L. McDonald, Marissa Birkmeier, Bryan Walker, Linda Cotton, \\ Laurie B. Lyons, Howard O. Straker, Margaret M. Plack \\ The George Washington University \\ School of Medicine and Health Sciences
}

\begin{abstract}
Time and space constraints, large class sizes, competition for clinical internships, and geographic separation between classroom and clinical rotations for student interaction with peers and faculty pose challenges for health professions educational programs. This article presents a model for effectively incorporating technology to overcome these challenges and enhance student engagement and interaction in traditionally face-to-face (FTF) health professions (physical therapy and physician assistant) curricula across learning environments (classroom to clinic). Four faculty members interested in redesigning a course or course unit(s) met with the IMPACT (Instructional Media and Programming to Advance Collaboration and Teaching) Initiative instructional design team. Instructional designers provided education, training, and support to faculty for increased use of technology within courses. Four exemplars using Blackboard ${ }^{\mathrm{TM}}$, videos, VoiceThread ${ }^{\circledR}$, and Twitter $^{\circledR}$ are described. Themes and "lessons learned" were developed from each of the exemplars. A model emerged for integrating technology into health professions curricula with an emphasis on engaging students in active, realistic, and social learning environments. This model demonstrates how technology can be integrated successfully into traditionally FTF health professions curricula to support learning outcomes essential for practice.
\end{abstract}

\section{Introduction}

Health science professional education must prepare graduates to perform competently in a dynamic and evolving healthcare system. In 2003, the Institute of Medicine (IOM) published goals for health professional education to meet the complex health needs of patients and the demanding nature of the healthcare environment (Greiner \& Knebel, 2003). The report describes five key competencies for clinicians, including: 1) delivering patient-centered care, 2) practicing in interdisciplinary teams, 3) using best evidence, 4) applying quality improvement, and 5) using informatics (Greiner \& Knebel, 2003). To achieve these competencies, clinicians must be competent, reflective, and collaborative problem-solvers. They must be prepared to apply the knowledge and skills they have learned in changing environments across the healthcare continuum with teams of other healthcare professionals (Berwick \& Finkelstein, 2010; Irby, Cooke, \& O’Brien, 2010).

To best prepare students for practice, health science professional education programs must use methods that help students learn in ways that are compatible with future requirements: that is, learning with others in an active environment. Currently, health professional education largely involves a 
combination of didactic classroom learning and clinical internships to prepare its graduates. The authentic nature of the clinical environment provides the learner many opportunities to begin to master the IOM's competencies. The didactic educational environment, however, often involves learners as passive recipients of lecture-based information and skill-based learning in non-authentic environments (McLaughlin et al., 2014), which is not compatible with what we know about the brain and how we learn (Jensen, 1998).

The purpose of this article is to present a model for effectively incorporating technology to enhance student engagement and instruction in traditionally face-to-face (FTF) health science (physical therapy and physician assistant) education. The inclusion of properly selected technologies can facilitate reflection, collaboration, and problem solving, all of which are essential for developing clinicians of the future.

\section{Literature Review}

Dewey (1938) believed that experience is a key to learning and described the importance of feedback to enhance learning from experience. Specifically, Dewey suggested learning occurs when: 1) the learner observes or experiences something, 2) compares that experience with prior knowledge, and 3) judges and makes meaning of that knowledge and experience for future purposeful action. Capitalizing on Dewey's work, Kolb (1984) presented four processes learners need to effectively use to attain new knowledge, skills, and attitudes: 1) concrete experience (ability to be fully and openly involved in an experience), 2) reflective observation (ability to critically reflect on and consider their experience from different perspectives), 3) abstract conceptualization (ability to formulate their observations into concepts), and 4) active experimentation (ability to apply these concepts in novel situations) (see Figure 1 modified from Kolb, 1984). The clinical environment provides ongoing experiential learning opportunities where attainment of new knowledge, skills, and attitudes is grounded in activities such as patient encounters, inter-professional meetings, and family interactions. Ongoing discussions and reflective opportunities enable students in the clinic to apply prior knowledge and experiences to new content and build new frameworks for future patient interactions and clinical decisions. However, to optimally engage in learning in the clinical environment, students must be given opportunities across the educational environment from classroom to clinic that facilitate discussion, reflection, problem solving, and application. Refinement of these skills is what will enable students to achieve the five competencies described in the IOM report.

Figure 1. Kolb's Experiential Learning Cycle (Kolb, 1984)

To best prepare students and graduates for future clinical work, health science educators should "teach with the brain in mind" using active-learning that encourages higher-level thinking (Jensen, 1998; Silberman \& Auerbach, 2006). Higher order thinking involves applying, analyzing, synthesizing, and evaluating concepts, which mirror the cognitive processes employed by clinical experts in clinical decision-making with patients (Bloom, Engelhart, Furst,

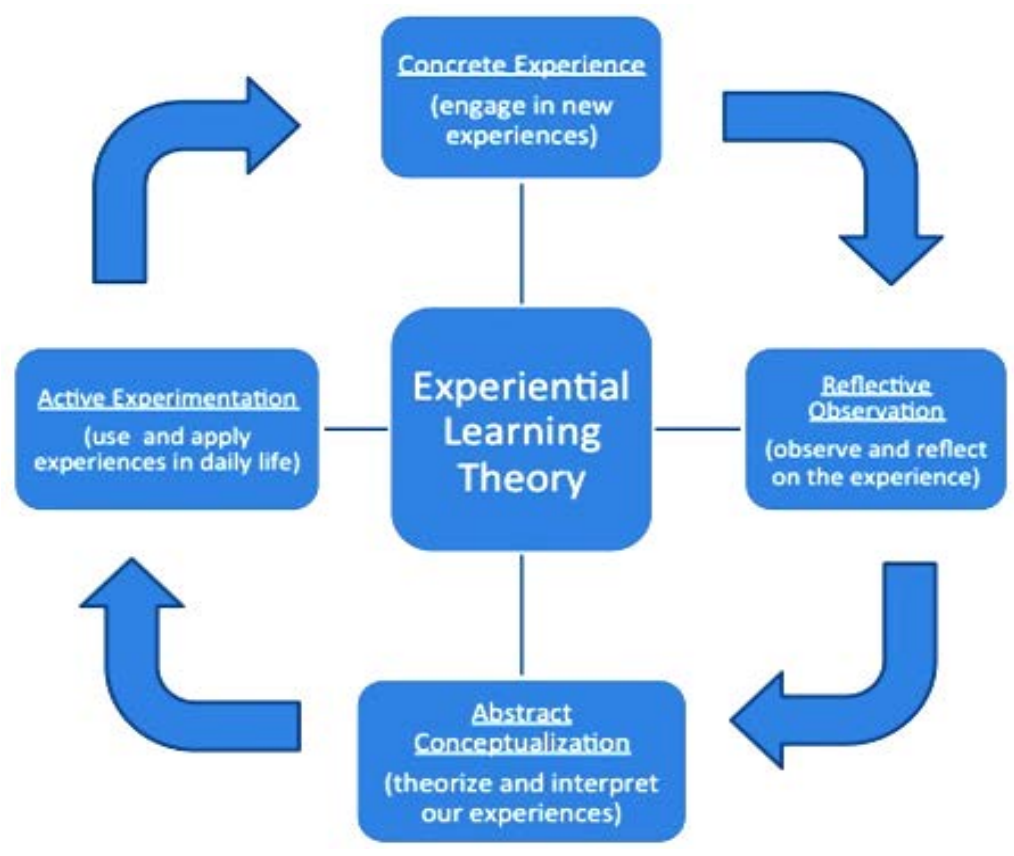


Hill, \& Krathwohl, 1956; Jensen, Gwyer, Shepard, \& Hack, 2000; Moulton, Regehr, Lingard, Merritt, \& MacRae, 2010). A classroom environment that combines presentation of new information with activelearning and reflective strategies creates an ideal learning environment for students to acquire these higher order cognitive processes and apply and retain new information (Jensen, 1998). Deviating from the traditional instructor-led lecture, active-learning strategies emphasize student-centered discussion, problem solving, and critical thinking. Active-learning strategies to improve in-class engagement that have been described in the literature include: Just-in-Time teaching, Learn Before Lecture (LBL), and the "flipped" classroom, as well as preparatory activities, games, puzzles, panels, fishbowls, jigsaws, roleplays, response cards, polling, and learning partners (Gleason et al., 2011; Marrs \& Novak, 2004; McLaughlin et al., 2014; Moravek, Williams, Aguilar, \& O’Dowd, 2010; Ruckert, Plack, \& Maring, 2014). Technology is often incorporated into these active-learning strategies to increase student engagement and interaction, as well as address space and time constraints. Active-learning strategies reinforce Kolb's cycle of experiential learning through discussion of concepts and sharing of ideas with others, reflection on those ideas, interpreting the ideas to make meaning out of them, and then applying them in the classroom and future clinical practice.

Beyond active engagement, the social context of the learning is also important to consider when designing instruction to facilitate the higher order thinking needed for clinical practice. To be an effective healthcare practitioner requires engaging socially and working collaboratively in teams. So, it is vital that academic programs help students learn how to work with others to solve complex problems and negotiate constructively in the solution-building process. This proposition is consistent with theories proposed by Bandura (1986) and Illeris (2003), which view learning as a social process requiring action and interaction within a social environment. Illeris argues the complexity of today's social environments, such as health care, requires educational interventions promoting accommodative learning (applying existing knowledge in new, unique situations) and/or transformative learning (simultaneous restructuring of cognitive, emotive, or social dimensions of learning), rather than mere memorization.

Figure 2. Collaborative Learning involving small and large group learning to help an individual make meaning in their learning process

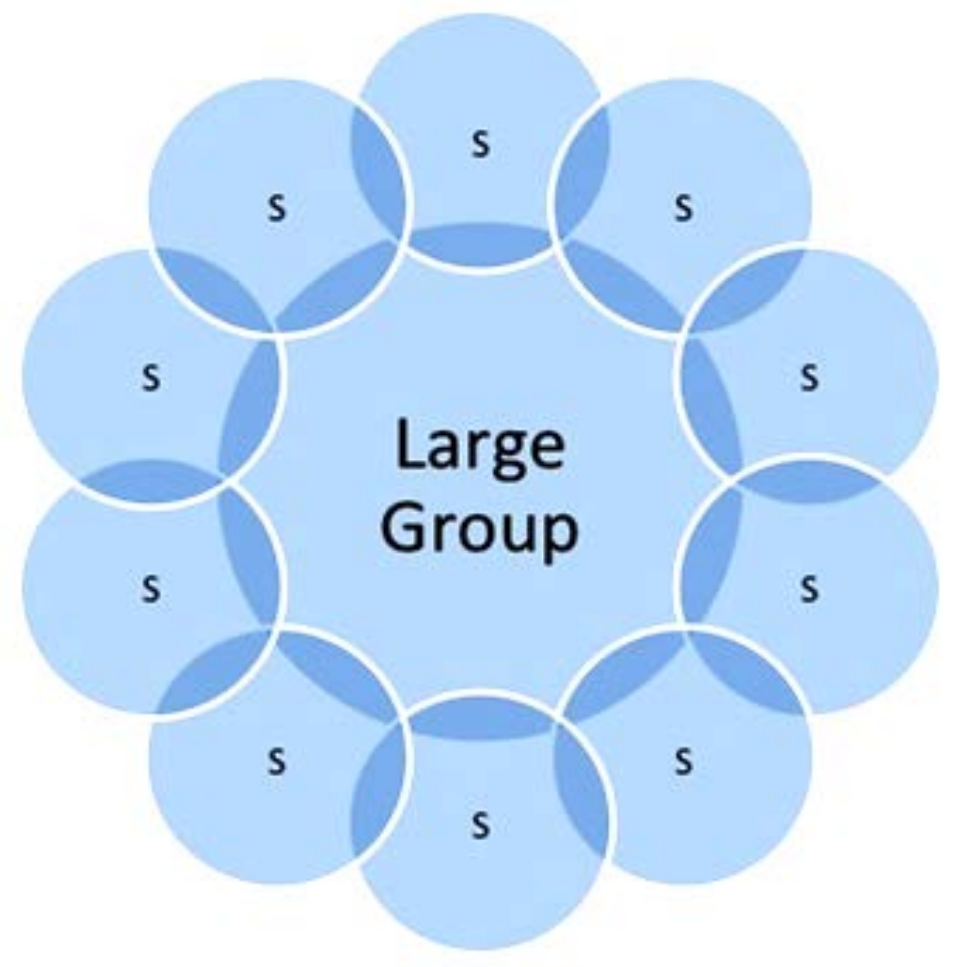


Collaborative learning is based on the assumption that "an individual person constructs his or her knowledge through the process of negotiating meaning with others...cognitive development is highly dependent on social interaction and collaboration with more capable and knowledgeable others" (So \& Bush, 2007, p. 3). Figure 2 illustrates collaborative learning through the presence of small interactive groups (represented by "S" clusters) within a larger learning group to contribute to an individual's "meaning making" process. The Community of Inquiry model is based on social constructivist principles for online learning (Garrison, Anderson, \& Archer, 2003; Garrison \& Kanuka, 2004). Based on this model, instructors aim to build the sense of community required to create a safe environment in which students can negotiate the meaning of controversial issues related to future practice (Garrison \& Anderson, 2003; Garrison \& Kanuka, 2004). Communities of inquiry require cognitive presence, social presence, and teaching presence. Building a sense of community among learners enables the cohesion necessary for supportive, open communication. As a consequence, students can critically debate controversial issues, which fosters reflection and critical thinking. Future health professionals will need to negotiate social environments in which they work to critically evaluate patient interventions. Promoting communities of inquiry within a classroom can allow future health professionals to experience the negotiation and critical thinking vital to future practice.

At The George Washington University (GW), technology is a key component of instructional design. Technology creates experiences and connects learners for social encounters spanning the classroom to clinic environments. During classes, technology can help prepare learners for FTF discussion and for clinic-related experiences through Blackboard or other learning management systems, video reflection, VoiceThread ${ }^{\circledR}$ or other asynchronous multimedia discussion tools, and social media (Michael, 2006). Technology supports social learning theories (Bandura, 1986; Garrison, Anderson, \& Archer, 2003; Garrison \& Kanuka, 2004; Illeris, 2003), enabling learners to negotiate meaning among their peers to promote higher levels of learning and critical thinking. Furthermore, technology helps students collaborate with one another, reflect individually and in small groups, and create strategies for successful future clinical practice. However, technology must be chosen appropriately to support specific learning objectives. Technology must be selected to support principles grounded in educational theory and based on evidence of how people learn (Clark \& Mayer, 2011; Mayer 2008). This selection includes presenting material in dual-channels (visual and verbal) which facilitates cognitive processing. Technology also appeals to millennial learners (Plack \& Driscoll, 2010) and can be utilized to create a more meaningful environment for learning than the classroom alone.

In this article, four GW Health Sciences Program exemplars are provided in which technology was used to help prepare students for clinical decision-making and reflection required in future clinical practice. These exemplars are rooted in experiential learning and social learning frameworks. Pedagogical goals, educational methods, course outcomes, and lessons learned will be shared. Finally, a model is presented for implementing technology to enhance course design and prepare learners for clinical practice based on experience in combination with educational pedagogy and learner preferences/values.

\section{Methods}

The Health Sciences Programs in the School of Medicine and Health Sciences at GW are comprised of three departments. All courses in the Department of Clinical Research and Leadership are delivered in an online format, while courses in the Department of Physical Therapy and Health Care Sciences and the Department of Physician Assistant Studies are primarily delivered in a face-to-face (FTF) format. In 2012, the Dean of Faculty Development began an initiative to enhance the use of blended learning, active-learning techniques, and technology in courses across health sciences, which is consistent with the strategic plan for the University. The Instructional Media and Programming to Advance Collaboration and Teaching (IMPACT) Initiative, described in the first article in this series, is designed to support teaching, scholarship, and collaboration among faculty, staff and administrators in 
Health Sciences. To support this initiative, two instructional designers provide education, training, and support to faculty redesigning their courses to incorporate increased use of technology.

Faculty interested in redesigning a course or course unit(s) were encouraged to meet with the instructional design team. Some faculty participated in a formal course redesign program (called Review, Refresh, review, or R3, as described in the first article in this series), which involved a comprehensive evaluation of course alignment followed by a structured course re-design process. Other faculty more informally took advantage of the IMPACT instructional design team and Supported Media for Research, Administration and Teaching (SMART) Lab (technology lab), as well as departmental resources and discussions with colleagues. This article presents several blended learning exemplars that resulted from the IMPACT Initiative and the support provided for its implementation.

Quantitative and qualitative methods were used to assess the outcomes of each exemplar. Data were collected using Likert scale surveys and open-ended questions resulting in qualitative comments. Students completed formative assessments during each course and/or summative assessments at the end of each course. Formative assessments-including anonymous online or in-class surveys—were utilized to solicit student feedback regarding instructional methods (including use of technology), course assignments, and level of engagement in the subject matter. Summative assessments via end-of-semester course evaluations provided additional information related to instructional design, instructor efficacy, and overall quality of learning in the course. Student feedback was reviewed and analyzed. Results from questions using a Likert scale were summarized using descriptive statistics. Results from the open-ended comments were categorized and themed. To optimize objectivity of the qualitative analysis, an external researcher not involved in any of the courses functioned as a peer reviewer (Merriam, 2002). The themes that emerged were applied to develop a model for blended learning.

\section{Results}

\section{Exemplar \#1: Using Technology to Create “Priming Activities” to Prepare Learners for In-class Engagement}

In the Physical Therapy Management of the Aging Adult course in the Doctor of Physical Therapy Program (PT) at GW, technology is used to create "priming activities"-that is, carefully and deliberately designed homework. These pre-class activities expose students to foundational content and specific critical thinking questions about the material before class. Thus, students are better prepared to apply the material and engage in higher level thinking activities during the FTF session. The priming activities are directly aligned with the course objectives and assessments and allow the learner to reflect and conceptualize their understanding of the content to prepare them for the active experimentation and discussion which takes place during the in-class session.

Priming activities, which were housed in the Blackboard ${ }^{\mathrm{TM}}$ learning management system, were used prior to each class session. They included reading articles, analyzing patient cases, watching videos, or preparing for in-class oral presentations. Before the FTF session, students accessed the required readings, critical thinking questions, and additional content (e.g. videos, podcasts, shared Google documents) on Blackboard $^{\mathrm{TM}}$. Figure 3 presents a sample of the Blackboard ${ }^{\mathrm{TM}}$ design. Regardless of the primer content or activities, the key component of the instructional design was incorporating the primer in the FTF session. Table 1 provides an example of priming activities and use of technology to maximize student engagement and application of information in class. 
Figure 3. Sample Blackboard ${ }^{\mathrm{TM}}$ Design for Priming Activities

\section{Week 10 -- Frailty, Exercise Adherence, Balance \& Fear of Falling (Combination of Week 9 \& 10)}

\section{Class Schedule}

Location:

\begin{tabular}{|l|l|}
\hline $1: 30-2: 20$ & Strategies to improve exercise adherence and self-efficacy with older clients \\
\hline & $\begin{aligned} \text { Lab Rotations } \\
\text { 2:30-4:30 }\end{aligned}$ \\
& $\begin{array}{l}\text { Frailty: Assessment \& Plan of Care Considerations } \\
\text { - Fear of Falling: Assessment \& Plan of Care Considerations }\end{array}$ \\
\end{tabular}

\section{Required Reading}

Cameron ID, Fairhall N, Langron C, et al. A multifactorial interdiscplinary intervention reduces frailty in older people: randomized trial. BMC Medicine. 2013;11:65. [Full text at Himmelfarb Library]

Petsursdottir U, Arnadottir SA, Halldorsdottir S. Facilitators and barriers to exercising among people with osteoarthritis: A phenomenological study. Physical Therapy. 2010;90:1014-1025. [Full text at Himmelfarb Library]

\section{Priming Activity}

Please answer the attached questions in preparation for class by using the readings and your knowledge from prior coursework. Submit your written response here before class begins.

\section{Class Materials}

Click here for the UPDATED class powerpoint

Click here for the lab handouts:

- Frailty: group worksheet \& Frailty info sheet

- Fear of Falling: handout

- Fall Assessment Guidelines: case example worksheet

\section{NPH Video for Lab}


Table 1. Description of a Class Session Using Priming Activities and Technology to Maximize In-Class Learner Engagement

\begin{tabular}{|l|l|l|l|}
\hline Topic & $\begin{array}{l}\text { Technology } \\
\text { Utilized }\end{array}$ & Pre-Class & FTF Session \\
\hline $\begin{array}{l}\text { Alzheimer's } \\
\text { Disease } \\
\text { AD) }\end{array}$ & $\begin{array}{l}\text { Blackboard } \\
\text { Electronic textbook } \\
\text { Video case } \\
\text { examples }\end{array}$ & $\begin{array}{l}\text { Students access Blackboard for } \\
\text { priming activity. Students read } \\
\text { text and article related to AD } \\
\text { and exercise interventions. } \\
\text { Students answer questions to } \\
\text { apply the reading content to a } \\
\text { patient case. Students also } \\
\text { answer a question to reflect on } \\
\text { prior clinical experiences with } \\
\text { individuals with AD and } \\
\text { describe effective and } \\
\text { ineffective communication } \\
\text { strategies with this patient } \\
\text { population. }\end{array}$ & $\begin{array}{l}\text { Students come to class and are } \\
\text { immediately put into groups to } \\
\text { share with one another their } \\
\text { personal experiences of } \\
\text { effective \& ineffective } \\
\text { communication strategies when } \\
\text { working with individuals with } \\
\text { AD. Whole-group discussion of } \\
\text { trends in these management } \\
\text { strategies followed. Students } \\
\text { then analyze a video of a staff } \\
\text { encounter with an individual } \\
\text { with AD in a skilled nursing } \\
\text { facility. Physical therapy } \\
\text { interventions and } \\
\text { communication strategies are } \\
\text { applied. }\end{array}$ \\
\hline
\end{tabular}

Student perceptions of the priming activities, active-learning strategies, and use of technology in the course were measured through student evaluations of the course design and the instructor. Student feedback was collected through a formative assessment one third of the way through the course (week 6) and through a summative assessment at the end of the course (week 15). It was important to complete a formative assessment mid-way through the course because this was the first time in the PT curriculum that the students completed homework activities in this format. Because the priming activities were pivotal to the course design, it was critical to measure student "buy in." Both formative and summative feedback provided the instructor with valuable information for ongoing course improvements within the semester and in subsequent semesters. Formative assessment questions included: 1) What do you find MOST helpful for your learning in the class? Why? 2) What do you find LEAST helpful for your learning in the class? Why? 3) What content remains unclear or "muddy" in your mind? 4) Discuss the efficacy of the different activities utilized in the course (e.g., priming activities, breakout activities, laboratory sessions, etc.). All 37 students completed the formative assessment prior to midterm. In response to the aspect of the course that was most helpful, the students responded using open ended comments related to priming activities, active-learning strategies, technology, and other activities (lecture, patient cases, and summary slides). Table 2 provides a summary of results and exemplar quotes. Students also provided feedback for specific course activities in an open text box. The majority of students commented positively on the priming activities $(n=33)$. Students also commented on how the priming activities helped them prepare for class and remain accountable for the material, engage in class more effectively, and remember the key points ("take-aways") from the assigned reading and class discussion. Similarly, summative feedback via the course evaluation related to technology was collected. Table 3 presents the results. 
Table 2. Formative Feedback at Week 6: What Do You Find MOST Helpful for Your Learning in the Class?

\begin{tabular}{|c|c|c|}
\hline $\begin{array}{l}\text { Course } \\
\text { Activity }\end{array}$ & Response & Exemplar Quotes \\
\hline $\begin{array}{l}\text { Priming } \\
\text { Activities }\end{array}$ & $\begin{array}{l}n=14 \\
(40 \%)\end{array}$ & $\begin{array}{l}\text { - } \quad \text { Priming activities are helpful because they encourage clinical } \\
\text { thinking/reasoning rather than just regurgitation of information } \\
\text { from the reading." } \\
\text { "The priming activities are helpful for class with keeping a } \\
\text { patient in mind during the session." } \\
\text { "The priming activities are a great way to put me in the proper } \\
\text { mindset before class-I know what to expect coming in." } \\
\text { "The priming activities [are most helpful]-I think the patient } \\
\text { case scenarios really help to supplement the lecture material." }\end{array}$ \\
\hline $\begin{array}{l}\text { Active- } \\
\text { learning } \\
\text { Strategies }\end{array}$ & $\begin{array}{l}n=16 \\
(44 \%)\end{array}$ & $\begin{array}{l}\text { - } \quad \text { All the application work-not merely lecture. I like that lecture } \\
\text { provides the framework but then the group work and lab exercises } \\
\text { drive home the points/themes." } \\
\text { "The format of lecture with small breakouts is helpful for staying } \\
\text { engaged." } \\
\text { "The active participation. It really helps me remember and learn } \\
\text { the information." } \\
\text { "I like having activities mixed in with class. It helps break the } \\
\text { information up into manageable chunks and apply it } \\
\text { immediately." } \\
\text { "Overall class is very interactive and it helps not only to remain } \\
\text { engaged but to grasp material more easily." } \\
\text { "I find lab very helpful for putting it all together." }\end{array}$ \\
\hline Technology & $\begin{array}{l}n=11 \\
(31 \%)\end{array}$ & $\begin{array}{l}\text { - "The layout of Blackboard is really helpful and I appreciate the } \\
\text { - "Vmount of time that went into making it so interactive." } \\
\text { - "Videos and case studies help put a patient picture in my mind." } \\
\text { efficiently and allows for personal organization. I also appreciate } \\
\text { the book being electronically available..." } \\
\text { "I really like having a schedule [on Blackboard] prior to class or } \\
\text { at the beginning o class of what we are going to do at what time. } \\
\text { It really helps me to better focus throughout class knowing what is } \\
\text { coming." }\end{array}$ \\
\hline
\end{tabular}


Table 3. Results of the Summative Course Evaluation at Week 15

\begin{tabular}{|l|l|l|}
\hline Criteria & Rating* & $\begin{array}{l}\text { \% Rating } \\
\text { “A Great } \\
\text { Deal” }\end{array}$ \\
\hline 1. Priming activities helped me learn the course material. & $\begin{array}{l}97 \% \text { rated this item } 3 / 4 \text { or } \\
4 / 4^{* *} \\
3.9 \pm 0.4 / 4.0(n=30)\end{array}$ & $94 \%$ \\
\hline $\begin{array}{l}\text { 2. The use of technology helped increase my level of } \\
\text { engagement with this course. }\end{array}$ & $\begin{array}{l}97 \% \text { rated this item } 3 / 4 \text { or } \\
4 / 4 * \\
3.7 \pm 0.5 / 4.0(n=30)\end{array}$ & $74 \%$ \\
\hline $\begin{array}{l}\text { 3. The quality of this course was improved by the use of } \\
\text { technology. }\end{array}$ & $\begin{array}{l}9 / 4 \% \text { rated this item } 3 / 4 \text { or } \\
4.7 \pm 0.5 / 4.0(n=30)\end{array}$ & $71 \%$ \\
\hline
\end{tabular}

*31 of 34 students completed the course evaluation anonymously online

** Ratings: 1=lowest; 4=highest

Despite the success of using technology through priming activities to create a more dynamic and active classroom environment in this course, there were a number of lessons learned by the instructor to consider for future implementation in this course.

1. Accountability is essential for the students. Student evaluations from the 2012 course offering showed students needed to have an external person hold them accountable for completing the preparatory work - despite their acknowledgement of the primers' value in their learning. Requiring students to submit their priming activity via Blackboard ${ }^{\mathrm{TM}}$ prior to the class session ensured all students completed the required reading and answered the application questions or other follow-up work in preparation for class discussion.

2. Integration of the priming activity during the in-class session is essential to grounding the learning. The instructor needed to establish a careful balance between revisiting the information provided in the primer "just enough" in the classroom to ensure all students had the basic foundation/knowledge, but not "so much" that the class session was merely duplicating work they did in the primer.

3. To maintain student buy-in, the primers must be a reasonable length. The instructor determined each priming activity should take one hour to complete. Some students, however, reported the primers taking longer. This emphasizes the importance of focusing on a few targeted objectives (two to three) for the priming assignment. Priming activities of a reasonable length are more likely to be completed by the students. Next year, the instructor plans to ask students to complete a weekly survey regarding how long the priming activity took to complete, to adjust and improve the primer design. 


\section{Exemplar \#2: Using Videos to Facilitate Clinical Decision Making and Reflection}

In the Clinical Skills 2 course in the Physician Assistant (PA) Program at GW, technology via video recordings facilitates critical reflection. Reflective practice is one way to achieve higher levels of learning and critical thinking in health sciences students (Plack \& Santasier, 2004), and technology-if applied properly - can facilitate this process. Video recording student performance of a clinical skill enables students to analyze and reflect on their performance, which has been show to increase skill competency (Kolb, 1984; Maloney, Storr, Morgan, \& Ilic, 2013; Schön, 1987). In medical and health sciences curricula, standardized patients are often used to simulate clinical experiences and teach and assess clinical skills, oral communication skills, and critical thinking. Standardized patients are an ideal form of learning and assessment in medical education because they simulate the true clinical environment (Downing \& Yudkowsky, 2000). Similar to a medical clinic, the student interacts with a previously unknown "patient," must establish rapport, use patient-friendly language, gain the individual's trust, and competently perform clinical skills. GW's Clinical Learning and Simulation Skills (CLASS) Center includes authentic medical examination rooms to simulate a realistic clinic environment.

Based on student performance in clinic and feedback from clinical preceptors, a specific clinical skill, the oral case presentation (OCP), was consistently observed as an area for improvement. The instructor, along with an instructional designer, developed a reflective practice activity utilizing video to improve students' completion of OCPs. The activity incorporated aspects of Kolb's (1984) experiential learning theory, including active-experimentation (completing the case presentation) and reflective observation via video. Students enrolled $(n=66)$ in a Clinical Skills course in the spring 2014 semester engaged in such an exercise. The students performed a standardized patient encounter for a focused and common medical complaint. For example, the patient had a chief complaint of shoulder pain or abdominal pain and the student had to take a focused history and perform the appropriate physical exam. Upon completing the simulated visit and exiting the examination room, the student was given several minutes to prepare for an OCP detailing the historical and physical exam data obtained, as well as a differential diagnosis and plan. The OCP was recorded and uploaded to a secured but shared platform (Google drive). Access to student videos was shared with selected individuals, including the system administrator, the course coordinator, the individual student, and the student's faculty advisor. The student's faculty advisor assessed the video using a rubric familiar to both faculty and students. Qualitative feedback was provided to the student regarding his or her performance. In addition, each student was required to view the OCP video, self-assess using the same rubric, and reflect upon his or her OCP.

The students completed an anonymous online survey about the OCP video activity. A total of $83 \%$ (54 of 66) responded, and of those $87 \%$ responded "yes" to the question: "Are there things you would do differently the next time you are asked to present a case?" Table 4 contains results and exemplar quotes. These comments suggest students need to further develop their clinical decisionmaking skills. Providing a brief and organized history required students to synthesize potentially large amounts of data to the most relevant aspects. Analyzing pros and cons of a differential diagnosis list required higher order thinking related to analyzing and evaluating data collected. This simulated clinical encounter allowed the students to reflect and gain insight on current practice to provide better future care. 
Table 4. Results of Formative Survey Regarding Students' Perceptions of OCP Video Activity

\begin{tabular}{|c|c|c|}
\hline $\begin{array}{l}\text { Question: "To what } \\
\text { extent do you agree } \\
\text { with the statements } \\
\text { below on a scale of } \\
0 \% \text { (not at all) to } \\
100 \% \text { (completely):" }\end{array}$ & Rating* & Exemplar Quotes \\
\hline $\begin{array}{l}\text { 1. Video recording } \\
\text { and evaluating my oral } \\
\text { case presentation was } \\
\text { a positive learning } \\
\text { experience. }\end{array}$ & $\begin{array}{l}74 \% \text { rated this } \\
\text { item as } 80- \\
100 \% \\
\text { agreement } \\
(\mathrm{n}=40)\end{array}$ & $\begin{array}{l}\text { - "... Really was a good learning process" } \\
\text {-I think we should do more of these... getting } \\
\text { recorded and having to self-evaluate myself made } \\
\text { it more official and I think showed me some of my } \\
\text { weaknesses." } \\
\text { "I think overall this was a very important session } \\
\text { that took place. Any areas of improvement are } \\
\text { made obvious for us to see. Rather than being } \\
\text { graded on how we thought we did, we can see for } \\
\text { ourselves the good and the bad that will overall } \\
\text { contribute to our progress in presentation skills." } \\
\text { "It was a valuable experience to watch my own } \\
\text { oral presentation, as it's a level of self-reflection } \\
\text { that I'm not accustomed to. I picked up on } \\
\text { automatisms that I was not aware of, so that's } \\
\text { something I'll try to modify in the future." }\end{array}$ \\
\hline $\begin{array}{l}\text { 2. [The OCP] activity } \\
\text { promoted the } \\
\text { development of my } \\
\text { oral presentation } \\
\text { skills. }\end{array}$ & $\begin{array}{l}69 \% \text { rated this } \\
\text { item as } 80- \\
100 \% \\
\text { agreement } \\
(\mathrm{n}=37)\end{array}$ & $\begin{array}{l}\text { - "I was clearly nervous but after listening to it, I } \\
\text { included more than I thought I did. I forgot to } \\
\text { mention the tenderness in her lower abdomen." } \\
\text { - "I admit to making a few errors when doing my } \\
\text { oral presentation, but I feel overall I have come a } \\
\text { long way with improving my skills. I need to } \\
\text { continue to work on little things like "ums" } \\
\text { between thoughts. With time, experience, and } \\
\text { better confidence I will be able to smooth out the } \\
\text { rough edges." } \\
\text { " } \text { "Go over pros and cons more when I give my } \\
\text { differential diagnosis." } \\
\text { "Improve on articulating physical exam findings, } \\
\text { as well as outlining a more detailed/explicit plan." } \\
\text { "I would make sure to time manage better, be less } \\
\text { redundant, more pith and succinct." }\end{array}$ \\
\hline
\end{tabular}

*54/66 students completed the survey (83\%)

** Rating scale: $0 \%$ (not at all); 20\%; 40\%; 60\%; 80\%; 100\% (completely) 
There were several lessons learned in the first trial of this activity for future improvement.

1. Technology can be intimidating. While there are many positive attributes to using this type of active-learning strategy, it did not appeal to all learners. The video camera was intimidating for some students.

2. Timing of feedback is important to the learning process. There was a time delay between the students completing the activity and the faculty feedback-it was not delivered immediately to the student. This delay may have prevented some learners from recognizing how they would use the feedback in future clinical application, as well as limit opportunities for successful practice.

3. Providing exemplars can help learning. A video example of a well-executed OCP for the students to have a frame of reference before completing the activity may benefit the learning experience.

4. Group reflection or application can enhance learning. Incorporating a group reflection or application of the OCP skills to another class activity may allow further the benefits of social learning.

\section{Exemplar \#3: Using VoiceThread ${ }^{\circledR}$ to Promote Critical Thinking, Collaboration, and Higher Levels of Learning}

In the Health, Justice, and Society (HSJ) course within the PA Program at GW, technology facilitates communities of inquiry during asynchronous and FTF class sessions. Incorporating the social interaction necessary to develop a learning community in a cohort of over 60 students can prove challenging in a traditional model of delivery. Fostering a sense of community becomes even more difficult in classes held in a theatre style lecture hall. In addition, students within the cohort represent different backgrounds, age groups, and levels of experience within healthcare settings, which creates challenges in designing a learning experience aligned with student needs and experience levels. Using VoiceThread $^{\circledR}$ technology enables instructors to develop small group communities of inquiry, allowing learners to engage in small group discussions in a safe environment before engaging in the larger classroom community.

In the summer of 2013, faculty re-designed HSJ from a traditional FTF course to a blended course. The re-design incorporated technology to maximize student collaboration, both in and out of the classroom. The blended learning environment enabled learners to collaborate, negotiate meaning, critically reflect, and apply what they were learning to new and novel situations (Illeris, 2003; Kolb, 1984). The course comprised both a weekly online (OL) component delivered through Blackboard ${ }^{\mathrm{TM}}$ and a weekly FTF component. Sixty-seven students were enrolled in the course. Students were assigned to smaller "learning teams" of six or seven students, in which they interacted in online activities and team projects for the duration of the semester. Over four weeks at the end of the semester, students had to apply knowledge gained regarding ethical healthcare practice to solve four complex patient cases related to future clinical practice.

The adoption of VoiceThread ${ }^{\circledR}$ for assignment submission maximized interaction among group members and between groups. VoiceThread ${ }^{\circledR}$ is a cloud application into which instructors and students can upload documents, images, presentations, audio files, and videos to share with private groups or the entire community. Viewers can comment on a given VoiceThread ${ }^{\circledR}$ by typing a message or by recording a voice or video message. The application can be integrated in learning management systems and can be used via mobile apps (www.voicethread.com).

Prior to discussing the four cases in their groups, students were asked to view a VoiceThread ${ }^{\circledR}$ presentation on ethics, conduct assigned readings, and take an individual ethics quiz. They then had to apply knowledge gained from these materials to develop a team solution to four distinct cases. Students were offered the opportunity to discuss cases both OL and in the FTF class session. In the final group assignment, students created a framework representative of the ethical aspects they felt were essential to 
future practice and presented them to the rest of the class using VoiceThread ${ }^{\circledR}$ as if they were presenting in person. Assignment completion required team members to negotiate and agree upon essential aspects. Table 5 presents the sequence of activities required in the online and FTF mediums.

Table 5. Sample Sequence of OL and FTF Learning Activities in HSJ

\begin{tabular}{|l|l|l|l|}
\hline Assignment & $\begin{array}{l}\text { Online activity Prior to } \\
\text { FTF }\end{array}$ & FTF Activity & $\begin{array}{l}\text { OL activity after FTF } \\
\text { class }\end{array}$ \\
\hline $\begin{array}{l}\text { Ethics } \\
\text { Cases }\end{array}$ & $\begin{array}{l}\text { Review related OL } \\
\text { readings and materials, } \\
\text { including case }\end{array}$ & $\begin{array}{l}\text { Resolve case and plan } \\
\text { VoiceThread } \\
\text { presentation in peer } \\
\text { groups } \\
\text { Discuss case resolution } \\
\text { in peer group either FTF } \\
\text { or OL }\end{array}$ & $\begin{array}{l}\text { Create and upload } \\
\text { VoiceThread }^{\circledR} \\
\text { presentation of case }^{\text {OL reflective journal }} \\
\text { entry }\end{array}$ \\
\hline
\end{tabular}

Course activities challenged students to negotiate differing opinions, synthesize various type of knowledge to create coherent presentations for classmates, view and discuss content from the presentations of other groups, and think critically about the knowledge they generated in comparison to other groups and in comparison to what may be required in future practice. Exemplar quotes below demonstrate higher order thinking by students in VoiceThread ${ }^{\circledR}$ regarding the presentations of other groups:

- "I also thought you guys did a nice job taking into account James and his genetic mutation possibly buying him some time. My question to your group is what would you do air lifting Janey to another hospital was not an option? Would it impact your choice of who gets what bed? Would anyone no longer receive a bed?"

- "What is the role of self-reflection and bias in the care of the patient? Knowing our limits as providers can help us become more self-aware practitioners in order to maintain our integrity with patients. Some hold strong beliefs that would inhibit them from performing certain procedures. To what extent should we deny certain care for the sake of our own beliefs?"

It was important to assess the students' evaluation of technology use in the course. Faculty conducted an anonymous online survey to assess reactions to the integration of technology within the course in relation to their perceptions of learning and engagement. Forty-three of the 66 students completed the survey (65\%). Table 6 below captures data relevant to different aspects of the course including: preparatory materials, discussions, and VoiceThread ${ }^{\circledR}$ activities. The results suggest that the course activities engaged over half of the students to think about and challenge their own assumptions, which requires high cognitive processing. It could be argued that while only $10 \%-20 \%$ of students found the VoiceThread $^{\circledR}$ presentations or activities helpful for their learning, these activities likely played a key role in the majority of students' higher participation in class. Among the 43 survey respondents, with regard to overall satisfaction with the blended course structure, 7 respondents (17\%) were not at all satisfied, 31 respondents (53\%) were somewhat satisfied, and 4 respondents $(10 \%)$ were satisfied. None of the respondents indicated that they were satisfied "a great deal." 
Table 6: Student Perceptions of Use of Technology in Blended Course

\begin{tabular}{|c|c|c|c|c|}
\hline \multirow[b]{2}{*}{$\begin{array}{l}\text { Survey } \\
\text { Question }\end{array}$} & \multicolumn{3}{|c|}{ Responses } & \multirow[b]{2}{*}{$\begin{array}{l}\text { Exemplar Quotes } \\
\text { In response to most effective and least } \\
\text { effect aspects of the blended course..... }\end{array}$} \\
\hline & $\begin{array}{l}1 \\
\text { Not at } \\
\text { all }\end{array}$ & $\begin{array}{l}2-3 \\
\text { Somewhat }\end{array}$ & $\begin{array}{l}4-5 \\
\text { Mostly to } \\
\text { “A Great } \\
\text { Deal” }\end{array}$ & \\
\hline $\begin{array}{l}\text { VoiceThread }^{\circledR} \\
\text { assignments } \\
\text { helped me learn } \\
\text { the course } \\
\text { content. }\end{array}$ & $\begin{array}{l}21 \% \\
(n=9)\end{array}$ & $\begin{array}{l}70 \% \\
(n=30)\end{array}$ & $\begin{array}{l}9 \% \\
(n=4)\end{array}$ & $\begin{array}{l}\text { - "Use of new/different technologies } \\
\text { (such as VoiceThread }{ }^{\mathbb{B}} \text { and online } \\
\text { lectures) facilitated learning."(most) } \\
\text { - "While I appreciate not having to sit } \\
\text { through all the presentations in } \\
\text { person, I think there is limited utility } \\
\text { to listening to other groups } \\
\text { presentations." (least) }\end{array}$ \\
\hline $\begin{array}{l}\text { OL discussions } \\
\text { encouraged me } \\
\text { to examine my } \\
\text { thoughts, beliefs, } \\
\text { or feelings } \\
\text { regarding course } \\
\text { topics. }\end{array}$ & $\begin{array}{l}12 \% \\
(n=5)\end{array}$ & $\begin{array}{l}67 \% \\
(n=28)\end{array}$ & $\begin{array}{l}21 \% \\
(n=9)\end{array}$ & $\begin{array}{l}\text { - "Online course discussions were the } \\
\text { most beneficial thing for me as far as } \\
\text { incorporating many peoples thoughts } \\
\text { and seeing others thoughts."(most) } \\
\text { "Online Discussions and Journal } \\
\text { entries seemed more like busy work." } \\
\text { (least) }\end{array}$ \\
\hline $\begin{array}{l}\text { FTF discussions } \\
\text { encouraged me } \\
\text { to examine my } \\
\text { thoughts, beliefs, } \\
\text { and or feelings } \\
\text { regarding course } \\
\text { topics. }\end{array}$ & $\begin{array}{l}0 \% \\
(\mathrm{n}=0)\end{array}$ & $\begin{array}{l}48 \% \\
(n=20)\end{array}$ & $\begin{array}{l}52 \% \\
(n=22)\end{array}$ & $\begin{array}{l}\text { - "Face to face discussion was the most } \\
\text { effective aspect. I think the topics we } \\
\text { tackled were important to talk about } \\
\text { and deal with in a face to face } \\
\text { setting."(most) } \\
\text { "Some of the time the conversation } \\
\text { was interesting, but mostly there were } \\
\text { too little people talking which is why I } \\
\text { thought the online collaboration was } \\
\text { better." (least) }\end{array}$ \\
\hline $\begin{array}{l}\text { OL journal } \\
\text { entries } \\
\text { encouraged me } \\
\text { to examine my } \\
\text { thoughts, beliefs, } \\
\text { or feelings } \\
\text { regarding course } \\
\text { topics. }\end{array}$ & $\begin{array}{l}7 \% \\
(n=3)\end{array}$ & $\begin{array}{l}67 \% \\
(n=28)\end{array}$ & $\begin{array}{l}26 \% \\
(n=11)\end{array}$ & $\begin{array}{l}\text { - "Being able to discuss in class what I } \\
\text { had been thinking about throughout } \\
\text { the previous few days. Also, the } \\
\text { journaling of my thoughts."(most) } \\
\text { "There was some amount of } \\
\text { redundancy between the online } \\
\text { discussion boards and journal } \\
\text { assignments; I recommend } \\
\text { consolidate into either journaling or } \\
\text { discussion boards." (least) }\end{array}$ \\
\hline
\end{tabular}

*43/66 students completed the survey (65\% overall response rate)

Rating Scale $=1($ not at all) to 5 (a great deal) 
Lessons learned in implementing this new blended course within a traditionally FTF curriculum included:

1. Explaining the purpose and value-added nature of technology is essential. This course was the only course in the PA program of study using a blended format. This could explain students seeming resistant to the integration of technology and an online component within the course design. In addition, students did not understand why OL discussion was necessary when the course also met FTF. Next year, this will be addressed by reinforcing how the OL components contribute to the process of learning and allow interactions/activities not possible in the FTF environment due to the constraint of time and space.

2. Reducing workload and redundancy. Students also found combinations of technology (e.g. OL journaling and OL discussion) redundant. In future course offerings, this redundancy will be addressed by reducing the number of OL journals and distinguishing discussion prompts from journal prompts to reveal distinct purposes aligned with learning objectives. Students also had difficulty recognizing distinctions between OL and FTF discussions. In future courses, this ambiguity will be address by emphasizing the relationship between both types of discussions and by ensuring that FTF discussions build upon OL discussion by offering new, perhaps more complex situations for analysis

\section{Exemplar \#4: Using Twitter ${ }^{\circledR}$ to Enhance Reflection}

In the Clinical Conference IV course within the PT Program at GW, technology facilitates communities of inquiry while students are in clinical internships. Students across health professions spend as much as $45 \%$ of their total training time engaged in clinical internships (Commission on Accreditation of Physical Therapy Education, 2013). When students are in clinical internships distributed over long distances, the opportunities for collaborative learning and the sense of community and connection with peers is often lost. OL tools provide an active platform for students to practice reflection and engage in professional communication within a connected social community (Anderson, 2007). In the fall of 2013, second year physical therapy students $(n=34)$ used Twitter ${ }^{\circledR}$, a micro-blog, to engage in active and reflective conversations following days spent in clinic. Since the assignment required synchronous, concise conversation, Twitter ${ }^{\circledR}$ was selected due to its character limitations and presumed popularity among the student cohort (Rockinson-Szapkiw \& Szapkiw, 2011).

The objectives of the activity were to develop concise but original reflective tweets, engage in active/reflective conversation with peers during the live tweet session, develop communication strategies to provide succinct, constructive feedback to peers in a professional manner, and develop future physical therapy professional goals. Students were in clinic five days over the course of the semester. Live tweet sessions were in the evenings of Week 1, Week 3, and Week 5 from $7 \mathrm{pm}$ to $11 \mathrm{pm}$. Prior to the first live tweet session, students were given an orientation to Twitter ${ }^{\circledR}$, assistance in setting up an account or a different account from their personal one, and instructions to privacy and netiquette rules for the class. For each session, students were given reflection starters to elicit specific reflections for their primary tweets. Sample tweets also were provided. For example, the Week 1 starter was: "I was surprised most in clinic by..." A rubric was used to determine the students' performance based on number of required tweets, quality of tweet content, and professional behaviors.

Thirty-three of 34 students completed a survey after assignment completion, and at least $70 \%$ responded in agreement that the objectives of the assignment were met. These survey statements were specific to reflection, professional engagement and discussion with peers, and development of professional use of social media. Students also provided comments on the summative course evaluation in which the assignment was placed. Some themes derived from the comments include that students found the assignment to be fun, short, and engaging and thought "it encouraged conversation and thoughtful reflection." In addition, some found it "immensely comforting and supportive" knowing that experiences were similar among their collective group of peers. Students also liked that the assignment was not time consuming in an already full semester of coursework. Students did provide some suggestions for 
enhancements for future implementation of this assignment. The primary improvements suggested were related to the functionality of Twitter ${ }^{\circledR}$ and the challenge of tracking different conversations. A few students suggested a pre-tweet session before the first live-tweet session to provide practice for those who had never used Twitter ${ }^{\circledR}$. Some students preferred to not have prompts for each session and would like more freedom in what they tweeted. Overall, students supported minimal to no changes to the assignment.

Based on the positive response from the students and achievement of the learning objectives, plans are to continue this assignment with future cohorts as an introductory reflection activity during clinical experiences. Lessons learned included:

1. Do not assume familiarity with technology. The assumption of graduate students being familiar with most social media platforms should not be made.

2. Orientation and practice is essential for buy-in and competence. Ample time for orientation to the social media platform must be included in the design of the assignment. About half of the students in this particular cohort had not used Twitter ${ }^{\circledR}$ which further supports the importance of a thorough orientation to this teaching tool. Future plans include providing practice sessions in class to allow students to acclimate to the technology in a setting with direct faculty support. Another change involves streamlining the readability of the conversations by using hashtags. This will hopefully allow students more of a chance to follow conversations, which will enhance their ability to efficiently and effectively engage and reflect collaboratively with their peers.

\section{Discussion}

The IOM's clinical competencies for health professionals require flexible, responsive, collaborative and adaptive thinkers. For students to develop this level of critical thinking necessary for clinical practice, educational programs must provide opportunities for active and collaborative engagement in required material. Delivering this education has its challenges, including (but not limited to) large class sizes, space constraints, faculty time constraints, increased competition for clinical internship placement, and geographical separation between the classroom and clinic locations for facultystudent interactions and student-student interactions. Each of the exemplars demonstrates that technology can assist the facilitation of higher order thinking while also addressing barriers to the delivery of health professional education. Table 7 exemplifies these challenges and how technology has provided solutions at GW. In addition, technology is helpful in creating meaningful and social learning experiences for learners. Each exemplar highlights mechanisms in which technology contributed to an active and engaging learning environment-whether physically in a classroom, a simulation center ("pseudo clinic”), or in the authentic clinical environment.

A number of themes emerged when evaluating the overall success related to learning and student value of technology within the exemplars. Most students liked the use of technology within the class setting and found it helpful to their learning because it enabled more active involvement with the content. This result is consistent with past literature related to flipped classroom and active-learning (Gleason, et al., 2011; Lage \& Platt, 2000; McLaughlin, et al., 2014; Prince, 2004). Of note, the students in the blended learning course had the least favorable view of technology. Despite this perception, it was clear from student performance in the classroom and the quality of presentations that technology helped students better prepare to engage in material at a higher level as compared to previous years of traditional FTF classes. The following themes emerged for at least three of four exemplars that were important for successful implementation: 1) clearly and explicitly describing purpose of technology with direct link to learning objectives/goals and learning experiences (whether in classroom, simulation lab, or clinic) helps learners understand "why" the methods are being used; 2) holding learners accountable for completion of activity (e.g. priming activities, VoiceThread ${ }^{\circledR}$ contributions, Twitter ${ }^{\circledR}$ ) prior to application learning experiences improves effectiveness; 3) providing feedback through rubrics or comments orients the learners to the goals of the activity (e.g. priming activities, video reflections, VoiceThread ${ }^{\circledR}$, Twitter ${ }^{\circledR}$ ); 
and 4) active and social participation within the learning experience aids student learning (e.g. priming activities, standardized patient interaction, FTF discussions, and Twitter reflections).

Table 7. Technology's Role in Addressing Barriers in Health Science Education

\begin{tabular}{|c|c|c|}
\hline Barrier & Exemplar & Specific Description \\
\hline $\begin{array}{l}\text { Large Class Size \& } \\
\text { Space Constraints }\end{array}$ & $\begin{array}{l}\text { Exemplar \#3: Hybrid learning } \\
\text { model }\end{array}$ & $\begin{array}{l}\text { VoiceThread }{ }^{\circledR} \text { provides opportunity for } \\
\text { students to engage in discussion OL to } \\
\text { alleviate problems with room size and } \\
\text { noise volume for FTF discussions. }\end{array}$ \\
\hline \multirow[t]{2}{*}{$\begin{array}{l}\text { Faculty } \\
\text { Constraints }\end{array}$} & $\begin{array}{l}\text { Exemplar \#2: Video case } \\
\text { presentations }\end{array}$ & $\begin{array}{l}\text { Faculty advisors can be incorporated into } \\
\text { providing feedback so that not all of the } \\
\text { burden of grading is placed on the course } \\
\text { director/core faculty member. } \\
\text { Feedback can be made according to the } \\
\text { faculty's schedule. }\end{array}$ \\
\hline & $\begin{array}{l}\text { Exemplar \#4: Twitter } \\
\text { reflective practice activity }\end{array}$ & $\begin{array}{l}\text { Concise reflections allow faculty member } \\
\text { to achieve critical reflective goals } \\
\text { without reading long reflective essays or } \\
\text { journals. }\end{array}$ \\
\hline \multirow[t]{2}{*}{$\begin{array}{l}\text { Increased competition } \\
\text { for clinical internship } \\
\text { placements }\end{array}$} & $\begin{array}{l}\text { Exemplar } \quad \# 1: \quad \text { Priming } \\
\text { activities }\end{array}$ & $\begin{array}{l}\text { Students complete weekly activities based } \\
\text { on patient case scenarios that directly } \\
\text { reflect common } \\
\text { presentations/diagnoses. }\end{array}$ \\
\hline & $\begin{array}{l}\text { Exemplar \#2: Video case } \\
\text { presentations }\end{array}$ & $\begin{array}{l}\text { Simulation provides students with a mock } \\
\text { clinical environment that directly mimics } \\
\text { clinical practice environment. }\end{array}$ \\
\hline Geographic location & $\begin{array}{l}\text { Exemplar \#4: Twitter } \\
\text { reflective practice activity }\end{array}$ & $\begin{array}{l}\text { Students feel a social connection to their } \\
\text { peers and faculty members through } \\
\text { online reflective discussion. }\end{array}$ \\
\hline
\end{tabular}

Each exemplar incorporated aspects of Kolb’s experiential learning model (see Figure 4 modified from Kolb, 1984) and social learning theory through communities of inquiry. Although not an explicit part of Kolb's learning model, it was evident that the social component of learning was an important factor for student learning at all aspects of the cycle. Regardless of the point on the learning cycle, the social component enabled learners to develop critical thinking skills and analyze material on a higher level. Reflective observation occurred both as individuals and as groups. At times, reflection even 
preceded the active-learning experience, as is the case with the priming activities and the VoiceThread ${ }^{\circledR}$ discussions. When reflection came first, most students valued the opportunity to consider the material and prepare for full, active participation in class. When experience came first, students learned through trial and error with time to reflect after. In retrospect, it may be helpful in the future to add more of a social learning context to the video OCP activity (Exemplar \#2). Although students did discuss their performance with an instructor, there may be added benefit of a large or small group discussion related to OCP skills strengths and areas for improvement.

Figure 4. Using Technology to Facilitate Experiential Learning (Kolb, 1984)

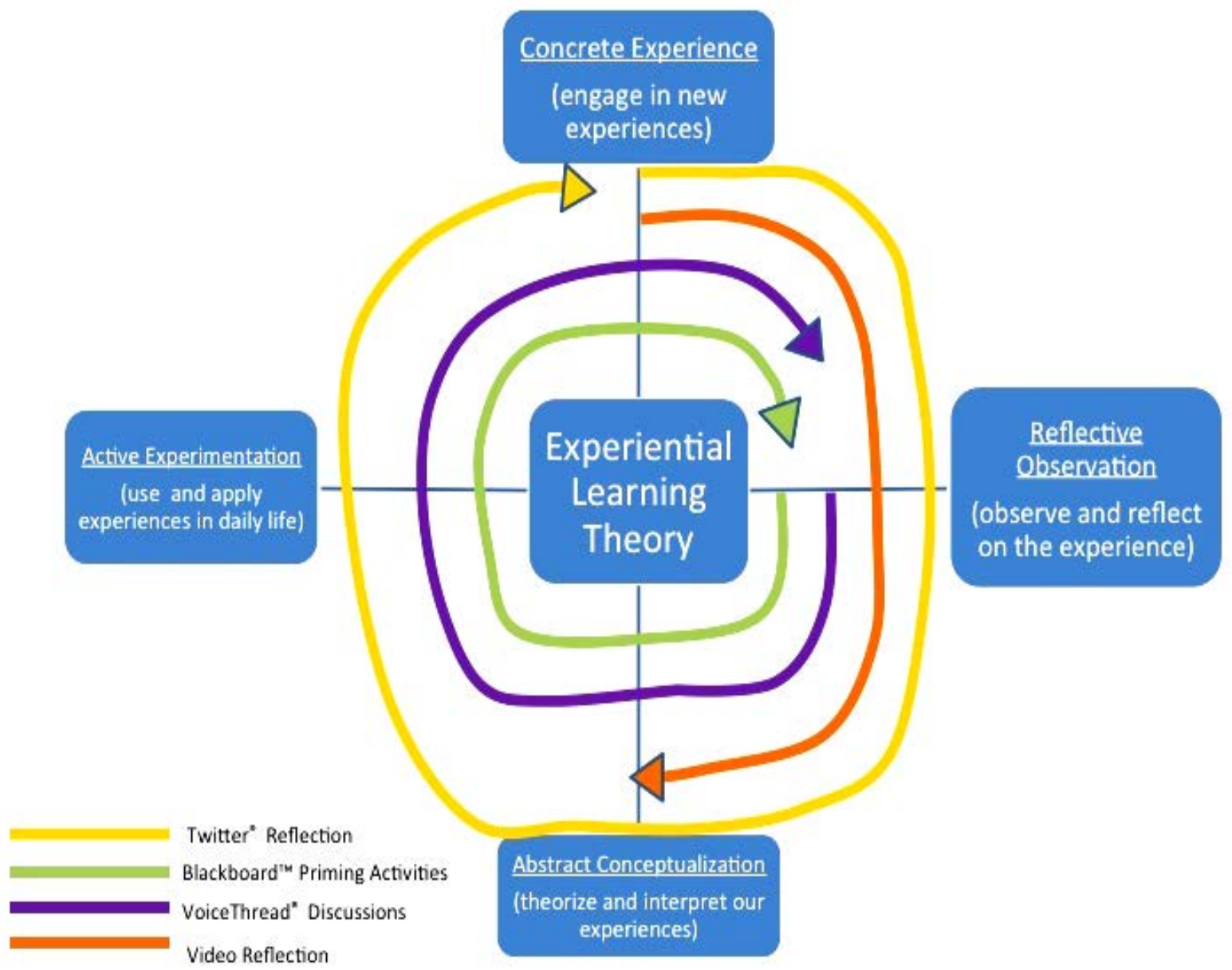

Through these exemplars, a model for planning courses that supports the development of skills related to competency, problem solving, reflection, and collaboration for health professionals emerged. In each exemplar, technology was utilized in a meaningful way to create active experiences and communities of inquiry for engaging application reflection of material at a higher level. This model is represented in Figure 5. A key component of this model is that technology provided these experiences across learning environments-from classroom to "pseudo clinic" to clinic-and through both synchronous and asynchronous means. Technology was a critical component of the achievement of higher order learning in each of these courses. 
Figure 5. Integration of Experiential and Social Learning Models in Health Science Education Using Technology

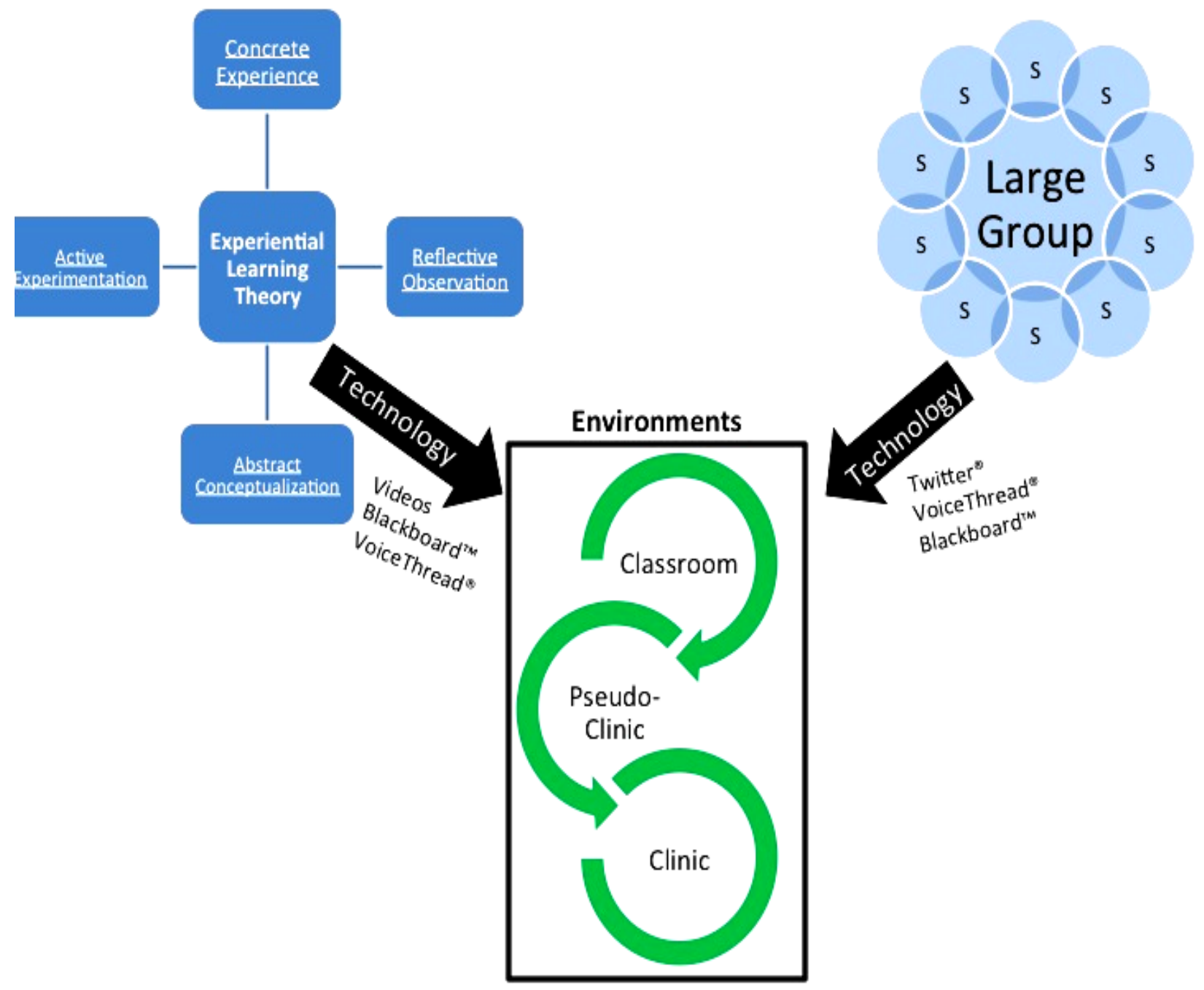

\section{Conclusion}

Technology can be used to engage learners in active, realistic, and social learning environments to best prepare students for the future demands of healthcare practice. Technology should be utilized after careful consideration of the desired learning objectives, as well as the "fit" of the individual course or course unit within the curriculum as a whole. Key contributors to the successful implementation of technology within the Health Sciences Programs at GW include: 1) the IMPACT Initiative, which is consistent with the strategic plan for the University 2) the instructional design team; 3) support from higher administration in terms of faculty time and encouragement; and 4) departmental champions and role models who encourage technology's use among colleagues. Using the model that emerged demonstrates how technology can be integrated into a traditionally FTF health professions curricula to support learning outcomes essential for clinical practice. 


\section{References}

Anderson, P. (2007). What is web 2.0? Ideas, technologies and implications for education. JISC Technology and Standards Watch, July 4, 2014.

Bandura, A. (1986). Social foundations of thought and action: A social cognitive theory. Englewood Cliffs, NJ: Prentice-Hall.

Berwick, D.M., \& Finkelstein J.A. (2010). Preparing medical students for the continual improvement of health and health care: Abraham Flexner and the new "public interest." Academic Medicine, 85, 856-865.

Bloom, B.S.; Engelhart, M.D., Furst, E.J., Hill, W.H., \& Krathwohl, D.R. (Ed.). (1956). Taxonomy of educational objectives: The classification of educational goals. Handbook 1: Cognitive domain. New York: David McKay.

Clark, R.C., \& Mayer, R.E. (2011). E-learning and the science of instruction: Proven guidelines for consumers and designers of multimedia learning. San Francisco, CA: Jossey-Bass.

Commission on Accreditation in Physical Therapy Education. (2014). 2012-2013 fact sheet: Physical therapist education programs. Alexandria, VA: Commission on Accreditation in Physical Therapy Education.

Dewey, J. (1938). Experience and education. New York: Simon \& Schuster.

Downing, S.M., \& Yudkowsky, R. (2009). Assessment in health professions education. New York: Routledge.

Garrison, D. R., Anderson, T., \& Archer, W. (2003). A theory of critical inquiry in online distance education. In W. G. Moore, \& T. Anderson (Eds.), Handbook of distance education (pp. 113-127). Mahwah: Erlbaum.

Garrison, D.R., \& Kanuka, H. (2004). Blended learning: Uncovering its transformative potential in higher education. Internet and Higher Education, 7(2), 95-105.

Gleason, B L., Peeters, M.J., Resman-Targoff, B.H., Karr, S., McBane, S., Kelley, K., Denetclaw, T.H. (2011). An active-learning strategies primer for achieving ability-based educational outcomes. American Journal of Pharmaceutical Education, 75(9), 186-198.

Greiner, A.C., Knebel, E. (Eds.). (2003). Health professionals education: A bridge to quality. Washington, D.C.: National Academies Press.

Illeris, K. (2003). Towards a contemporary and comprehensive theory of learning. International Journal of Lifelong Education, 22(4), 396-406.

Irby, D. M., Cooke, M., \& O'Brien, B. C. (2010). Calls for reform of medical education by the Carnegie foundation for the advancement of teaching: 1910 and 2010. Academic Medicine, 85(2), 220-227.

Jensen, E. (1998). Introduction to brain-compatible learning. San Diego, CA: Brain Store.

Jensen, G.M., Gwyer, J., Shepard, K.F., \& Hack, L.M. (2000). Expert practice in physical therapy. Physical Therapy, 80(1), 28-52.

Kolb, D. (1984). Experiential learning: Experience as the source of learning and development. Englewood Cliffs: Prentice-Hall.

Lage, M.J., \& Platt, G. (2000). The internet and the inverted classroom. Journal of Economic Education, 31(1), 11. 
Maloney, S., Storr, M., Morgan, P., \& Ilic, D. (2013). The effect of student self-video of performance on clinical skill competency: A randomized controlled trial. Advances in Health Sciences Education, 18(1), 81-89.

Marrs, K.A., Novak, G. (2004). Just-in-time teaching in biology: creating an active learner classroom using the internet. Cell Biology Education, 3, 49-61.

Mayer, R.E. (2008). Applying the science of learning: Evidence-based principles for the design of multimedia instruction. American Psychologist, 63(8), 760-769.

McLaughlin, J. E., Roth, M. T., Glatt, D. M., Gharkholonarehe, N., Davidson, C. A., Griffin, L. M., Mumper, R. J. (2014). The flipped classroom: A course redesign to foster learning and engagement in a health professions school. Academic Medicine, 89(2), 236-243.

Merriam S.B., Associates. Qualitative research in practice: Examples for discussion and analysis. San Francisco: Jossey-Bass, Inc.; 2002.

Michael, J. (2006). Where's the evidence that active-learning works? Advances in Physiology Education, 30(4), 159-167.

Moulton, C., Regehr, G., Lingard, L., Merritt, C., \& MacRae, H. (2010). 'Slowing down when you should': Initiators and influences of the transition from the routine to the effortful. Journal of Gastrointestinal Surgery, 14(6), 1019-1026.

Plack, M. M., \& Driscoll, M. (2011). Teaching and learning in physical therapy: From classroom to clinic. Thorofare, NJ: Slack.

Plack, M., \& Santasier, A. (2004). Reflective practice: A model for facilitating critical thinking skills within an integrative case study classroom experience. Journal of Physical Therapy Education, 18(1), 4-12.

Prince, M. (2004). Does active-learning work? A review of the research. Journal of Engineering Education, 93(3), 223-231.

Rockinson-Szapkiw, A.J., \& Szapkiw, M. (2011). Engaging higher education students through tweeting. Retrieved from http://digitalcommons.liberty.edu/cgi/viewcontent.cgi?article=1205\&context=educ_fac_pubs

Ruckert, E., Plack, M.M., \& Maring, J. (2014). A model for designing a geriatric physical therapy course grounded in educational principles and active-learning strategies. Journal of Physical Therapy Education, 28(2), 69-84.

Schön, D.A. (1987). Educating the reflective practitioner. San Francisco, CA: Jossey-Bass.

Silberman, L., Auerbach, C. (2006). Active training : A handbook of techniques, designs, case examples, and tips. San Francisco, CA: Pfeiffer.

So, H., \& Brush, T. A. (2008). Student perceptions of collaborative learning, social presence and satisfaction in a blended learning environment: Relationships and critical factors. Computers \& Education, 51(1), 318-336. 
